\title{
Comparison of select major elements within the Apollo basalt suite via cluster analysis
}

\author{
A. J. GawronskA ${ }^{1}$, M. R. Hughes ${ }^{2}$, C. L. MCLeOD ${ }^{1}$
}

${ }^{1}$ Department of Geology and Environmental Earth Science, Miami University, Oxford $\mathrm{OH}$. (correspondence: gawronaj@miamioh.edu)

${ }^{2}$ Statistical Consulting Center, Miami University, Oxford $\mathrm{OH}$.

The bulk rock composition of basaltic rocks can be utilized to investigate and constrain the processes occurring during the crystallization of a magma as it cools and ascends from its source region. Based on current Apollo basalt compositional data, the largest bulk major element differences exist with respect to the abudances of $\mathrm{Ti}, \mathrm{Al}$, and $\mathrm{K}$ oxides [e.g. 1]. The variations in composition observed thruought the Apollo basaltic suite with respect to these elements may be explained by the depth of melting, degree of partial melting, and/or assimilation/fractional crystallization processes. In this work, we apply cluster analysis to select major elements ( $\mathrm{Si}, \mathrm{Mg}, \mathrm{Fe}, \mathrm{Ti}, \mathrm{Al}, \mathrm{K}, \mathrm{Ca}$ ) to statistically evaluate compositional variation throughout the Apollo lunar basalt suite(s), and to evaluate the potential relative significance of geological processes that occur from source to surface in lunar basaltic magmatic systems. Through this work we will additionally evaluate whether the sampling location of a mission is a statistically significant variable which correlates to compositional characteristics. Hierarchal cluster analysis (an unsupervised statistical learning technique) [e.g. 2] will be carried out at Miami University's Statistical Consulting Center. Various cluster aggregation methods will be performed and evaluated, and optimal obtained cluster classifications for the samples will be evaluated for goodness of fit to known mission and/or group classifications. By considering each sample independent of each other and of the respective mission they were collected during, we may be able to make broader connections regarding the evolution of basaltic magmas within and on the Moon. We anticipate that this work will corroborate the inferences that processes operating to differentiate lunar magmas may be relatively wide-spread and planetary-wide. Samples from Apollo 12 and 15, as well as those from the Apollo 11 and 17, sites are similar compositionally and therefore likely record similar petrogenetic histories [1, 3].

[1] Neal \& Taylor (1992) Geochim. Et Cosmochim. Acta 56 (6), 2177-2211. [2] Hastie et al. (2009) The Elements of Statistical Learning. [3] Shearer et al. (2006) New Views of the Moon: Reviews in Mineralogy \& Geochemistry 60 (1), 365-518. 